\title{
El gobierno por agencias y autoridades adminis- trativas independientes y su vinculación con la Función de Transparencia y Control Social.
}

The government by independent administrative agencies and authorities and its link with the Transparency and Social Control Function

\section{Msc. Andrés Aguilar Chamorro*}

Consejo de Aseguramiento de la Calidad de la Educación Superior, Ecuador

Infomación del Artículo

Original - Ruptura, 2020

Artículo recibido / Received: 9 de octubre, 2020

Artículo aceptado / Accepted: 8 de diciembre, 2020

\section{Citación}

Aguilar, A. (2020). El gobierno por agencias y autoridades administrativas independientes y su vinculación con la Función de Transparencia y Control Social. Revista Ruptura Asociación Escuela de Derecho PUCE. Edición 2020, p (305-346).

DOI: $10.26807 /$ rr.vi02.27

Resumen: El gobierno a través de agencias independientes es una situación global que en cada una de las diferentes realidades se ha ido asentado en menor o mayor medida. Este artículo inicia con concepciones teóricas de aproximación al estudio de las agencias

* Licenciado en Ciencias Jurídicas y Abogado por la Pontificia Universidad Católica del Ecuador (2013). Máster en Análisis Político y Asesoría Institucional por la Universidad de Barcelona (2016). Máster de Derecho Constitucional por la Universidad de Sevilla (2020). Actualmente es asesor de la Comisión de Carreras y de la Comisión de Universidades del Consejo de Aseguramiento de la Calidad de la Educación Superior (CACES). Correo electrónico: araguilarch@gmail.com 
independientes para contar con los conceptos claros y verificar su implementación en el Ecuador. Continúa con la referencia a autoridades administrativas independientes que ya existían en el Ecuador desde inicios del siglo XX y que se impulsaron en 2008 con la incorporación constitucional de la Función de Transparencia y Control Social, especialmente con su órgano central, el Consejo de Participación Ciudadana y Control Social, sobre lo cual se hace un análisis en específico la parte final. Este artículo busca verificar hasta qué punto la constitucionalización de las autoridades independientes fue una herramienta efectiva para la neutralización política de este tipo de instituciones y para la consecución de sus objetivos originarios.

Palabras clave: Agencias independientes; Autoridades administrativas independientes; Ecuador; Órganos autónomos; Función de Transparencia y Control Social; Consejo de Participación Ciudadana y Control Social.

Abstract: Government through independent agencies is a global situation that in each of the different realities has settled to a lesser or greater extent. This article begins with theoretical conceptions of approach to the study of independent agencies to have clear concepts and verify their implementation in Ecuador. It continues with the reference to independent administrative authorities that have already existed in Ecuador since the beginning of the 20th century and that were promoted in 2008 with the constitutional of the Transparency and Social Control Function, especially with its central body of the Council for Citizen Participation and Social Control, about this an analysis is made in the final part. This article tries to verify to what extent the constitutionalization of the independent authorities was an effective tool for the political neutralization of this type of institutions and for the achievement of their original objectives.

Keywords: Independent agencies; Independent administrative authorities; Ecuador; Autonomous bodies; Function of Transparency and Social Control; Council for Citizen Participation and Social Control. 


\section{Introducción}

El aparataje estatal es una configuración compleja que desde el momento que empezó a implantarse en los estados modernos ha estado en constante evolución. Si bien hasta la fecha son reconocibles muchos de los postulados que sirvieron como base ideológica y teórica para su nacimiento, desde el siglo XVIII ha corrido mucha agua bajo el puente. El hecho de que las funciones del Estado superen las expectativas de padres fundadores, revolucionarios o emancipadores que fundaron a estos Estados va de la mano con la historia de la humanidad, el avance de la economía, la sociología y la política como catalizadores de cambios formales y materiales. Pensemos que estos constituyentes originarios concibieron al Estado moderno como uno solo y trino. En mayor o menor medida este dogma de los poderes Ejecutivo, Legislativo y Judicial es inherente a la mayoría de las realidades, por lo menos en el papel. Sin embargo, cada vez es más evidente que hay resquicios de poder que se resisten a ser etiquetados dentro de estos poderes "clásicos". En este espacio gris se desarrollan las agencias o autoridades independientes (AAI), independientes de otros poderes y que han sido concebidas para temas concretísimos de interés estatal, hasta que en la actualidad han llegado a formar parte indispensable de la ingeniería constitucional de cada estado. El tratamiento de las AAI en el mundo no ha sido unívoco, es por eso aquí se tendrá una mirada global a otras realidades y a concepciones teóricas para finalmente aterrizar con este tipo de instituciones que no son ajenas al Ecuador, sino quizá poco estudiadas.

\section{Naturaleza de las agencias y autoridades administrativas independientes}

El principio de la separación de poderes del Estado es el punto de arranque de este documento debido a que las agencias o autoridades administrativas irrumpen en el escenario constitucional y administrativo como "agujeros negros" que flotan en el entramado del Estado sin que pueda decirse que pertenecen a uno u otro Poder. Este consabido principio de organización política ya era tema de discusión desde la Grecia clásica, sin embargo, serían Blackstone, Locke 
y Montesquieu quienes darían las bases doctrinarias para su implementación a escala constitucional. La separación de poderes del Estado se estableció en Europa como un contrapunto al absolutismo del siglo XVIII, lo cual se difundió en Occidente hasta América donde se implementó como un sistema político posterior al periodo colonial del continente. Es así como en las primeras constituciones de Francia y Estados Unidos se estableció en su parte orgánica que el poder debía estar fragmentado. En un inicio no estaba claro cuántos y cuáles serían los poderes, con el paso del tiempo a más del poder Ejecutivo y Legislativo habría de acompañarle la independencia del poder judicial. Sería Montesquieu en El Espíritu de las Leyes quien señalaría: "hay en todo Estado tres especies de Poderes: el Poder legislativo; el Poder ejecutivo de las cosas que dependen del Derecho de gentes, y el poder ejecutivo de las cosas que dependen del Derecho civil." (Montesquieu, 1942). En la Constitución francesa post Revolución Francesa queda explícita la separación de estos tres poderes, se canoniza como premisa constitucional y con ello se esparce por el mundo jurídico "occidental" hasta la fecha (Clavero, 2005).

Este principio obliga a que los estados se construyan en esta triple dirección para así garantizar, en teoría, el respeto a los límites establecidos para cada uno en las normas positivas que los prevén. A pesar de este loable objetivo, en palabras de García de Enterría y Fernández, este encuadre apretadísimo de un estado tricéfalo cercenaría la esencia sociológica del Estado, pues los órganos-poderes públicos son parte de un ente superior; y no concebir otra forma de estructurar el poder podría convertir al ser humano en prisionero de su propia creación (García de Enterría \& Fernández, 1997). La ficción de un Estado tripartito es una construcción que ha servido para el establecimiento de los estados modernos con altos y bajos, con su debida justificación y su lógica, pero no reflexionar y cuestionar los límites que este traje a medida tiene, sería por lo menos ingenuo, más aun cuando la realidad se ha encargado de demostrar que la concepción de Estado va más allá de Ejecutivo, Legislativo y Judicial.

Para García-Trevijano Fos al existir necesidades de índole social, económica y política es insostenible mantener esta estructura inalterable, de ahí que no sería descabellado que el poder se dividiera en 
4 o 5 poderes (García-Trevijano, 1968), tal como sucede en la Constitución China de $1931^{1}$, la Constitución de Venezuela de $1999^{2}$ o la Constitución ecuatoriana de $2008^{3}$. Las nuevas dimensiones en las que el Estado se ha ido involucrando paulatinamente, han traído consigo que la invariabilidad de la tripartición del Estado se rompa poco a poco. Esto es visible con la aparición también paulatina de instituciones alejadas e independientes de estos poderes, las autoridades y/o agencias administrativas independientes (AAI). Este fenómeno ha generado que este concepto, que en un inicio era la excepción a la regla, ahora sea la generalidad en las estructuras administrativas de las entidades públicas y sus relaciones en un sinnúmero de países.

Las leyes aprobadas, salvo contadas excepciones, no pueden ser ejecutables sin el impulso de una autoridad intermedia y generan dudas de su ejecución, es por eso que en un inicio las agencias y autoridades administrativas independientes se crearon para ayudar a atender las tareas que la administración iba asumiendo de forma paulatina. (Mashaw, 2006) Con el intervencionismo que en los Estados Unidos se fue acrecentando a finales del siglo XIX se vio la necesidad de implementar nuevas y más variadas instituciones administrativas, lo cual además servía para inyectar experiencia,

1 La organización institucional del Estado se articulaba a través de la teoría, inicialmente elaborada por Sun Yat-sen, de los cinco yuanes (poderes), que añadía a los tres poderes clásicos ya conocidos - legislativo, ejecutivo y judicial- otros dos poderes adicionales de control: el yuan de los exámenes, encargado del control en el acceso a los cargos públicos y el yuan de control en el plano administrativo y financiero de todos los órganos estatales. (Ayala, 2005) La larga marcha constitucional de la República Popular China: el período Mao Tse-tung. Revista de estudios políticos (129), 39-87.

2 La Constitución venezolana de 1999 hasta la fecha divide al Estado en: Poder Legislativo, Poder Ejecutivo, Poder Judicial, Poder Ciudadano y Poder Electoral.

3 La Constitución ecuatoriana de 2008, inspirada en la división hecha en Venezuela, hasta la fecha divide al Estado en las siguientes Funciones: Función Ejecutiva, Función Legislativa, Función Judicial, Función de Transparencia y Control Social y Función Electoral. 
profesionalismo y bipartidismo en un sistema de gobernanza que estaba totalmente "infectado" por el juego político (Mashaw, 2008).

Indudablemente, el quiebre de la concepción clásica de división de poderes se vio influenciada por la crisis del Estado liberal clásico y con la entrada de un Estado social más intervencionista ${ }^{4}$. Manuel García Pelayo justifica que se vaya más allá de los tres poderes para alcanzar los objetivos estatales de forma más eficaz. En su opinión tanto el crecimiento de los poderes de la tecnoburocracia, así como la intervención de las organizaciones en el proceso estatal se sustentan en un nuevo principio de legitimidad inherente al Estado 'manager' y que, si no rigurosamente proclamado, no es por eso menos sentido. Esto se traduce en que la eficacia sería lo que otorgue legitimidad a ciertos órganos, eficacia entendida como la capacidad para satisfacer las demandas crecientes que plantea la sociedad (García Pelayo, 1987).

La sustitución de este Estado burocrático, imprevisible, confuso y conflictivo se hace por el poblamiento de una multitud de agencias y autoridades independientes que se encargarían de optimizar los resultados de las intervenciones públicas. Con ellas se busca ge-

4 El Estado liberal que el mundo conoció en el siglo XIX, aquel que se le atribuía la conocida locución francesa laissez faire, laissez passer, concebía libertad absoluta en el ámbito económico: libertad de producción, libertad de competencia, libertad de mercado, libertad de trabajo, libertad de comercio y libertad de consumo. Pero dicha concepción cambia cuando se da la crisis de 1929 y la gran depresión que estuvo presente en toda la década de los treinta. Dada la importancia e influencia de la economía estadounidense, la crisis se internacionalizó y trajo nefastas consecuencias para la mayoría de países europeos y los que estaban estrechamente relacionados con éstos. Esto dio paso al apogeo de la doctrina del intervencionismo estatal basada en las propuestas del economista británico John Maynard Keynes y su obra central “Teoría general de la Ocupación, el Interés y el Dinero", la cual se fundamentaba en la demanda agregada, y dadas las circunstancias de la época establecía la intervención estatal para incrementar el consumo y la inversión, como medida para corregir el sistema capitalista. (Lazzarato, 2015) Neoliberalism, the financial crisis and the end of the liberal state. Theory, Culture \& Society, 32(7-8), 67-83. 
nerar confianza hacia la acción del poder público, que posibilite la aprobación de los ciudadanos. La crisis de la Administración sigue en la mira en la actualidad, la gestión política a pesar de contar con el voto popular como respaldo, se encuentra en medio de una profunda crisis de legitimidad. Se la acusa de ineficaz, nada transparente, que persigue en el fondo intereses particulares y que solo busca repartirse el botín político. Esto no hace más que acrecentar el apoyo a contar con una gestión administrativa profesionalizada, no contaminada por intereses políticos y que se maneje con criterios exclusivamente técnicos. Hoy hay muchos sectores que se muestran adeptos a apostar por las administraciones independientes como una separación visible del Estado entre sus entes políticos y sus entes de gestión administrativa.

A pesar de esto, tal como lo advierte Andrés Betancor, esta decepción o incluso indignación en contra del juego político y su infección en los entes de la administración, no debería ser suficiente para mitificar la fórmula de las AAI, pues cuentan con sus propios males y no puede considerárseles tan solo por su naturaleza, instituciones más eficientes y objetivas, ni podrían serlo a costa de principios capitales del Estado constitucional (Betancor, 1994, pp.234-244). Queda aún la duda, en concreto que implica ostentar el título de AAI.

\section{1. iAgencia independiente, autoridad independiente $\mathrm{u}$ órgano autónomo?}

Si se analiza el caso concreto de EE. UU., vemos que su doctrina ha zanjado como término adecuado independent agencies ${ }^{5}$ para distinguirlas de otros organismos del Estado (Datla \& Revesz, 2013, p.776). Reino Unido las ha denominado quangos el cual es un acrónimo de quasi

5 En la actualidad el gobierno cuenta con un listado de las agencias federales que se consideran como tal para los más variados deberes, entre las cuáles por ejemplo se tiene la constancia de: The Central Intelligence Agency (CIA), The Federal Trade Commission (FTC), The National Aeronautics and Space Administration (NASA), The Social Security Administration (SSA), The Smithsonian Institution (SI). 
autonomous non governmental organisations. Alemania por su parte para referirse a este fenómeno lo hace como Funktionale Selbstverwaltungsträgern (Instituciones titulares de autoadministración o instituciones autónomas) ${ }^{6}$. En Francia se las bautizó como autorité administrative indépendante ${ }^{7}$. La influencia de la definición francesa permeó en España e hizo que sea su traducción "autoridades administrativas independientes”, el término se ha utilizado en ese país y, no de forma categórica pero si generalizada, también en Latinoamérica.

Las AAI en Chile se han basado en la creación de superintendencias que son adscritas a ministerios, a pesar de esta escasa independencia, se las denomina autoridades administrativas independientes. En Perú, Bolivia y Colombia se ha determinado en la redacción de sus constituciones vigentes (1991, 1993, 2009, respectivamente) la existencia de los llamados "órganos constitucionalmente autónomos", y se los ha designado como de igual jerarquía al Ejecutivo, Legislativo o Judicial, de ahí que las AAI nacen de sus constituciones, sin que estas instituciones se agrupen dentro de un Poder específico.

En el Ecuador han existido infinidad de formas de referirse a estos órganos, sin llegarse a una conclusión definitiva, a veces se los confundía con órganos de control o simplemente se los denominaba como "otros organismos del Estado". En la actualidad muchas autoridades independientes ecuatorianas se agrupan dentro de la Función de Transparencia y Control Social, sin aún contar con una etiqueta definida, lo que sí es claro es que comparten las características esenciales de este tipo de instituciones.

6 En Alemania, a diferencia de lo que ocurre en los otros países, no resulta difícil determinar cuáles son las "autoridades independientes", pues son aquellas instituciones que, expresamente por ley, gozan de autonomía (Selbstverwaltung), aunque formalmente pertenezcan a la Administración indirecta (descentralizada)

7 El Parlamento Francés expidió la Ley Orgánica Nro. 2017-54 y la Ley Ordinaria Nro. 2017-55 el 20 de enero de 2017; que buscaba la clarificación y racionalización de las autoridades independientes, aquí se fijaron reglas en común y la creación de un estatuto de funcionamiento único para todas las instituciones seleccionadas por el legislador. 
Por lo tanto, nos referiremos a todas estas instituciones como $\mathrm{Au}-$ toridades Administrativas Independientes (AAI) por ajustarse a las características de su composición y diferenciación. Esto incluye a las diferentes denominaciones utilizadas sin distinción alguna, sino más bien para su agrupamiento en una categoría jurídica específica. Además, el término englobaría también a las agencias independientes anglosajonas por compartir los rasgos característicos que los distinguen de otro tipo de instituciones.

\subsection{Características de las AAI}

En la búsqueda del origen de las AAI es necesario delimitar cuáles podrían ser consideradas como tal y cuáles no. Debido a la compleja organización de los Estados esto puede ser más difícil de lo que parece, en palabras de Bilbao, las AAI por sí mismas constituyen una categoría organizativa sumamente heterogénea, para estas no existe un patrón concreto que sirva como modelo para su identificación, de hecho hay una amplia tipología (Bilbao, 1999, p.164). Esto puede deberse a que la estructuración de las AAI obedece más que nada a razones técnicas o económicas que estaban imprevistas.

Apoyémonos en las características que atribuye en su tesis doctoral Hugo Sánchez Hernández (Sánchez, 2015) por su análisis global y comparado con la realidad estadounidense, inglesa, francesa, española y colombiana.

a) Para él, las AAI son personas jurídicas de derecho público, con personalidad jurídica propia, es decir con autonomía para su auto organización; de gestión del personal a su servicio; y de auto disposición de su patrimonio. Esto, evidentemente, permitiría reducir las posibilidades de que el gobierno y el resto de la Administración condicionen de manera indirecta su actividad.

b) En segundo lugar, las normas por las cuales se rigen deberían ser especiales y privativas. Esta característica y su carácter público tienen el efecto de que las AAI se encuentren sujetas a su propia ley y además se encuentren vinculadas con el ejercicio de su actividad. 
c) Tercero, no deberían estar sujetas al poder de tutela y de dirección a las cuales el resto de las instituciones se someten, en síntesis, deberían ser independientes.

d) Los miembros de los órganos rectores y representantes de las AAI deberían contar con un periodo fijo en su cargo y solo podrían ser removidos por causales muy específicas. En contraposición a la mayoría de los altos cargos directivos de otro tipo de administraciones, que son de libre nombramiento y remoción. Hay otras modalidades de limitación, como la atribución de nombramientos a órganos no administrativos. En determinados casos, los nombramientos pueden ser realizados por el Ejecutivo o el Legislativo, previo acuerdo o delimitación con otro poder del Estado. Además, hay casos en que se encarga al Poder Judicial o una autoridad ajena al nombramiento, el cese de las autoridades por incurrir en causales específicas.

Hasta aquí las características propuestas inicialmente por este autor, sin embargo, evidentemente hay más elementos que considero se deberían tomar en cuenta, los cuales apunto a continuación sin interrumpir con los literales que como guía se utilizaron en el enlistado.

e) El surgimiento de estas instituciones dentro de los diferentes sistemas jurídicos por lo general obedece a momentos en los cuales el intervencionismo estatal se ha encontrado con áreas especialmente "sensibles", estas pueden ser económicas, estratégicas o vinculadas al ejercicio de derechos fundamentales. Manuel García Pelayo a más de coincidir con este criterio, matiza que esta injerencia específica se da gracias a la legitimidad de la existencia autónoma de estas organizaciones, en virtud de su funcionalidad, para satisfacer las necesidades sociales. Para él, en estos ámbitos el Estado ha considerado que es más importante the principle of performance por sobre the principle of authority, se persigue que haya mayor eficiencia, por sobre dilemas de legitimidad (García, 1987).

f) Se les encarga el ejercicio de potestades sustantivas para la regulación y el control de un sector determinado. La mayoría de las veces se trata de potestades de regulación diversas, que engloban capacidad de autorización, inspección y sanción (Vergara, 2017). 
g) Son instituciones con un refuerzo en su neutralidad política, que se apoya en la preparación técnica profesional relacionada al ramo específico de los representantes de las AAI. Para esto en algunos casos se fijan requisitos mínimos exigidos por alguna norma de carácter obligatorio. Es así que para estas designaciones se confiaría en criterios de expertos por encima de los políticos, en síntesis, criterios de tecnócratas. (Pomed, 1993), (García, 1993). Esta neutralidad política estaría por encima de la ideología del gobierno, el accionar de las AAI no responde al discurso del gobierno, cuenta con una neutralidad política reforzada y donde el government speech ${ }^{8}$ no debería incidir.

h) En mi opinión es característico que las AAI son difíciles de encasillar dentro de un poder clásico del Estado, desde su parte orgánica y funcional sus miembros y acciones cuentan con controles diferentes al resto de instituciones. Así mismo, sus miembros cuando son cuerpos colegiados provienen de diferentes poderes o incluso desde la sociedad civil.

Con esto se pretendería alcanzar objetivos diversos como: la transparencia informativa, la seguridad nuclear, la estabilidad monetaria, el buen funcionamiento del mercado de valores o la defensa de la intimidad frente al uso indebido de la informática. Soluciones a problemas que afectan al conjunto de la sociedad y cuya proyección temporal se extiende más allá de la vida de los gobiernos de turno.

Con base en los elementos que preceden, considero que una definición que abarca en líneas generales las características de las AAI

8 El government speech se asocia con el concepto acuñado por la Corte Suprema de los Estados Unidos que señala que todo gobierno ha de poder articular un discurso ideológico no neutral a través de sus actos, esto se enfrenta a las diferentes concepciones políticas existentes en la sociedad, y su control, en un Estado democrático, corresponde al proceso político y no a los jueces. Para mayor desarrollo al respecto y su problemática, véase: Vázquez Alonso, V. J. (2017). La neutralidad del Estado y el problema del government speech. Revista de Estudios Políticos, 177, 13-55. doi: https://doi.org/10.18042/cepc/rep.177.01. 
y que sirve para diferenciar de otro tipo de instituciones que componen el aparataje estatal sería: Las Autoridades y/o Agencias Administrativas Independientes son personas jurídicas autónomas, de derecho público, no identificables con alguno de los poderes clásicos del Estado, cuya designación y remoción de representantes se hace de manera independiente, a personas que cumplen con requisitos mínimos que obedecen a preparación técnica o profesional, por un periodo fijo en el plazo, con neutralidad política reforzada y que se establecieron para regular un sector muy específico en el cual el Estado consideró que era más óptimo que el juego político no intervenga para garantizar su eficiencia.

\section{Orígenes de las autoridades administrativas independientes en el Ecuador}

\subsection{Las agencias independientes en EE. UU.}

El primer antecedente del fenómeno de las agencias y autoridades administrativas independientes ocurrió en los Estados Unidos. El Congreso de este país creó en 1887 la Interstate Commerce Comission (ICC), organismo encargado entre otras cosas, de velar por el servicio de ferrocarriles comerciales que cruzaban el país. Aunque en un inicio la palabra independencia no se tomó en cuenta para su establecimiento, la conformación de esta Comisión dio pie a que se la considere de hecho muy independiente, ya que exigía que sus miembros provengan de partidos políticos diferentes y que sus cargos sean fijos sin la interferencia de otras autoridades. Su categorización como agencia federal independiente tuvo que esperar para concretarse hasta 1930 con el New Deal (Kirti \& Revesz, 2013).

El mayor desarrollo y estudio de las agencias independientes se dio justamente en el periodo del New Deal estadounidense. El New Deal buscaba una transformación constitucional y administrativa que permitiera al gobierno federal lidiar con los múltiples problemas 
sociales y económicos, producto de la "Gran Depresión". Consistía en una serie de políticas impulsadas por el presidente F. D. Roosevelt para una acción positiva del Estado, una intervención que promovía que las instituciones sean independientes, proactivas, técnicamente expertas y de orden apolítico para estimular reformas técnicas para recuperar al Estado (Sunstein, 1987). En este escenario, las agencias federales tenían una posición determinante en la dirección política del país, por su carácter experto (Vázquez, 2018, p.7)

Para ir perfilando las características de las Agencias en los EE. UU. el Tribunal Supremo ha generado jurisprudencia que analiza estos organismos $^{10}$, de ahí que a partir de estas resoluciones se puede verificar cuáles han sido las concepciones por las que las AAI han tenido que pasar a través del tiempo.

En el periodo del presidente Ronald Reagan y con el trasfondo de la Guerra Fría, al ser las agencias independientes imprescindibles para hacer realidad la nueva orientación de la política económica del país, en buena parte desamortizadora de los propios valores del New Deal (Vázquez, 2018, pp.13-14), se emitió la sentencia Chevron U.S.A., Inc. V. Natural Resources Defense Council, 467 U. S. 837 (1984) Inc., una de las decisiones más importantes respecto al papel de las agencias federales

9 También conocida como "Crisis del 2019", se le considera la mayor crisis financiera a nivel mundial en el siglo XX. Se originó en Estados Unidos a partir de la caída de la bolsa de valores de New York en octubre de 1929. Sus efectos se esparcieron por la mayoría de los países y entre estos estaba la caída de la renta nacional, los ingresos fiscales, los beneficios empresariales, el comercio internacional y los precios; así como la dramática subida del desempleo. La recuperación progresiva no sería hasta mediados de la década de los 30 o incluso hasta durante la Segunda Guerra Mundial. Véase (Sunstein, 1987).

10 Para poder acercarse a este fenómeno es esencial tener en consideración que los Estados Unidos de América cuenta con un sistema jurídico derivado del Common Law británico, de ahí que su control constitucional sea abstracto y el sistema de jurisprudencias obligatorias emitidas por la Corte Suprema (stare decisis) muchas veces perfila los roles de los organismos que componen su Administración, incluyendo a las agencias independientes. 
dentro de la administración ${ }^{11}$. Para poner esta decisión en contexto, tenemos que en 1977 el Congreso reformó la Clean Air Act (Ley del aire libre de contaminación) para obligar a los estados a cumplir con los estándares de calidad del aire establecidos por Agencia de Protección Ambiental (Environmental Protection Agency EPA), debiendo establecer un programa de permisos que regulara las principales stationary sources (fuentes estacionarias) nuevas o modificadas de contaminación del aire, la ley no establecía que se entiende por "stationary source". Por su parte, la EPA aprobó un reglamento que entendió fuente como "cualquier equipamiento en una planta que producía contaminación”. Pero en 1981, la EPA adoptó una nueva definición que permitía a una planta existente obtener permisos para adquirir nuevo equipamiento que no cumpliera con los estándares, siempre y cuando el total de las emisiones de la planta en su conjunto no incrementaran. Varios grupos ambientalistas, incluido el Consejo de Defensa de los Recursos Naturales (Natural Resources Defense Council NRDC), cuestionaron la disposición contraria a la Ley. El Tribunal de Apelaciones de los Estados Unidos para el Circuito DC descartó la regulación de la EPA como inapropiada para un programa promulgado para mejorar la calidad del aire. Ante lo cual, en la sentencia del Tribunal Supremo, por unanimidad, se establece que la regulación hecha por esta agencia independiente es una interpretación razonable de "stationary source" (fuente estacionaria) que se

11 En el artículo de Jorge Pérez Alonso, (2011) sobre el auge y ocaso de la Deferencia Chevron, el autor afirma que desde la expedición de esta sentencia pasó a convertirse en la resolución más estudiada, analizada y citada por la doctrina y jurisprudencia norteamericana. En el tratado de Derecho Administrativo y políticas de regulación de Breyer y otros (Breyer, Sunstein, Spitzer, \& Stewart, 2002), citado en el artículo de Pérez Alonso se afirma lo siguiente: "In a remarcably short period, Chevron has become one of the most cited cases in all of American law. Indeed, it may have become the most frequently cited case of all time. As of December 2001, Chevron had been cited in federal courts over 7000 times -far more than three far better known and much older cases Brown v. Board of Education, Roe v. Wade and Marbury v. Madison- and indeed far more often than the three of them combined! In terms of sheer number of citations, Chevron may well qualify as the most influential case in the history of American public law". 
encontraba dispuesto en la Clean Air Act. El Congreso no tenía una interpretación específica para el término y el reglamento emitido por la EPA era una opción de política razonable.

Esta decisión establece dentro del sistema norteamericano la deferencia a favor de las agencias independientes en la interpretación jurídica cuando no haya una previsión legislativa expresa o la misma sea de interpretación dudosa pudiendo los tribunales intervenir, pero sin que ello suponga imponer su propia interpretación o criterio, sino que la revisión judicial debe circunscribirse a determinar si la posición de la agencia a la hora de interpretar el texto legal es permisible o acorde con el mismo y, en caso de que tal interpretación administrativa no sea arbitraria o manifiestamente contraria al texto legal, los tribunales deben otorgar deferencia a la misma, sin que quepa en modo alguno al tribunal sustituir la misma con criterios o construcciones propios (Pérez, 2011).

En las últimas décadas la deferencia Chevron se ha puesto bajo la lupa y el propio Tribunal Supremo ha pintado matices para su aplicación restringiéndola para ciertos casos específicos y bajo ciertas condiciones. En la actualidad las agencias independientes en los Estados Unidos se han consolidado como un mecanismo fundamental para mantener el equilibrio de los poderes del Estado, desde un punto de vista constitucional. En la actualidad el gobierno cuenta con un listado de las agencias federales que se consideran como tal para los más variados deberes, entre las cuáles por ejemplo se tiene la constancia de las famosas CIA, NASA y otros ámbitos variadísimos entre sí.

\subsection{Latinoamérica y la Misión Kemmerer}

Después del fin de la Primera Guerra Mundial se sintieron en Latinoamérica dos efectos verificables: el incremento de la influencia estadounidense en la región a través de la inversión externa y el regreso al patrón de oro como base del sistema financiero. Esta influencia en los sectores comercial y político se debía principalmente al debilitamiento y destrucción europea después de la "Gran Guerra", es así como entre 1913 y 1929, los Estados Unidos lograron separar la 
influencia británica de este territorio (Naranjo, 2017). Sobre esto Drake señala lo siguiente:

(...) en 1913, Gran Bretaña había estimado \$ 532 millones invertidos en las cinco repúblicas andinas, mientras que Estados Unidos tenía solo \$ 72 millones. Dieciséis años después, la inversión de Inglaterra había aumentado solo un 14 por ciento, mientras que la de los Estados Unidos había aumentado, según el entusiasmo, en más del 1200 por ciento. (Drake, 1995, p.11)

El vehículo con el cual los Estados Unidos influyeron en el subcontinente fue la Misión Kemmerer, que en realidad fueron varias misiones que operaron entre 1919 y 1931, contratadas por algunos gobiernos latinoamericanos para realizar una serie de propuestas de remodelación de los sistemas monetarios, bancarios y fiscales de estos países. El líder de estos trabajos era Edwin Walter Kemmerer, economista estadounidense, profesor de Economía de la Universidad de Princeton (Posso, 2016). Las misiones estuvieron integradas por distintos colaboradores expertos en banca, contabilidad, organización tributaria y auditoría, se realizaron en los siguientes países, con los siguientes resultados:

- Guatemala (1919): actuó como consejero del gobierno en la creación del Banco Central de Guatemala y en otras reformas económicas.

- Colombia (1923): asesoró al Presidente Pedro Nel Ospina. Fruto de su gestión se fundó la Contraloría General de la República y el Banco de la República.

- Chile (1925): asesoró al gobierno de Arturo Alessandri Palma. Sus propuestas se materializaron en el Banco Central de Chile, la Superintendencia de Bancos y la Contraloría General de la República.

- Ecuador (1926): asesoró a la administración de Isidro Ayora, quien instauró el Banco Central del Ecuador, la Superintendencia de Bancos y la Contraloría General de la República. 
- Bolivia (1928): asesoró al gobierno de Hernando Siles. Sus propuestas se plasmaron en el Banco Central de Bolivia, la Superintendencia de Bancos y la Contraloría General de la República.

- Perú (1930): asesoró la Junta de Gobierno que presidía en ese entonces Luis Miguel Sánchez Cerro. Fruto de sus recomendaciones se crearon el Banco Central de Reserva y la Superintendencia de Banca.

Además, como asesor financiero particular, en 1917 Kemmerer sirvió al gobierno de México asistiendo a la Comisión de Reorganización Administrativa y Financiera (Gozzi \& Tappatá, 2010).

Estas instituciones tuvieron un desarrollo propio en cada una de sus realidades, sin embargo, poseían en común la característica de buscar desligarse de la influencia gubernamental ejercida sobre el manejo bancario y bursátil. Los bancos centrales buscaban otorgar la atribución de emitir la moneda local con un respaldo en oro, las superintendencias de bancos se conformaron para controlar el accionar de los bancos que estaban acrecentando su incidencia en sectores políticos; y las contralorías pretendían ser el vigilante para que la administración se ciña a sus propias normas no solo estatutarias y de funcionamiento, sino que los presupuestos e inversiones realizadas se ejecuten de acuerdo a la planificación programada. Tal como se pude advertir la Misión Kemmerer incidió directamente en la conformación de las primeras autoridades administrativas independientes en esta parte de Latinoamérica.

\subsection{Las AAI en Ecuador}

El caso ecuatoriano es particular pues no ha existido una aproximación doctrinaria específica, sin embargo, las instituciones que se considerarían como AAI, han sido agrupadas en algunas Constituciones con nombres que no ayudan a su entendimiento (Aguilar, 
2007, p.98). Tal es así que, en la Constitución de $1946^{12}$, se las agrupó como "Organizaciones varias" al no poder incluirlas en los poderes clásicos del Estado. En el caso de la Constitución de $1967^{13}$ en el capítulo "otros organismos del Estado". La Constitución de $1978^{14}$ las incluyó simplemente como "organismos del Estado" y un subapartado para "organismos del control". La Constitución de 1998 ${ }^{15}$ convirtió a todas estas organizaciones en "organismos de control". En la Constitución vigente publicada en $2008^{16}$, se aglutinó a la mayoría de las autoridades independientes dentro de la Función de Transparencia y Control Social, sin decantarse por una etiqueta concreta.

El aparecimiento de las primeras AAI en el Ecuador se generó a partir de 1927 en el sector financiero y bancario con el Banco Central, la Contraloría y la Superintendencia de Bancos, mismas que Kemmerer solicitó fueran de independientes de la autoridad gubernamental (Alemán, 2002). El reconocimiento constitucional de estas instituciones se daría en la Constitución Política de 1946, donde el constituyente señalaría que se garantizaba su estabilidad y autonomía.

A este listado se le sumaría en los años 60 la primera superintendencia diferente a la de Bancos, la de Compañías, que vería la luz el 27 de enero de 1964, mediante Decreto Supremo Nro. $164^{17}$ que dictó la primera Ley de Compañías en el Ecuador. En esta Ley se contemplaba ya la figura del Superintendente de Compañías. En 1967 la Constitución de ese año la incluiría en el Capítulo V del Título X "De Otros Organismos Del Estado".

A esto le seguiría ya en los años 90 una superintendencia encargada de las telecomunicaciones, mediante la Ley Especial de Telecomuni-

12 Publicada en el Registro Oficial Nro. 773, de 31 de diciembre de 1946.

13 Publicada en el Registro Oficial Nro. 133, de 25 de mayo de 1967.

14 Publicada en el Registro Oficial Nro. 800, de 27 de marzo de 1979.

15 Publicada en el Registro Oficial Nro.1 de 11 de agosto de 1998.

16 Publicada en el Registro Oficial Nro. 449, de 20 de octubre de 2008.

17 Publicado en el Registro Oficial Nro.181, de 15 de febrero de 1964. 
caciones de $1992^{18}$, el Congreso Nacional creó la Superintendencia de Telecomunicaciones (SUPERTEL), dirigida por un Superintendente. Por su parte, la Constitución 1998 fue el primer antecedente en la historia constitucional que estableció requisitos técnicos para fungir como superintendente en general, incluyendo al Superintendente de Telecomunicaciones, el segundo inciso del artículo 223 señalaba que era necesario tener al menos 35 años, título universitario relacionado a la función y experiencia de por lo menos diez años en el ejercicio de su profesión, avalada por notoria probidad. La Superintendencia de Telecomunicaciones funcionaría hasta el año 2015, cuando sus funciones fueron asumidas directamente por el Ejecutivo.

En la actualidad, la Función de Transparencia y Control Social asumió la titularidad de todas las superintendencias y creo nuevas dependencias, entre esas, la Superintendencia de Economía Popular y Solidaria que se creó formalmente en mayo 2011, con la expedición de la Ley Orgánica de Economía Popular y Solidaria ${ }^{19}$, la Superintendencia de Poder y Control del Mercado que se instituyó por orden de la Ley Orgánica de Regulación y Poder del Mercado ${ }^{20}$, la Superintendencia de Información y Comunicación, en adelante SUPER$\mathrm{COM}$, fue una autoridad administrativa independiente que se creó en 2013 a través de la Ley Orgánica de Comunicación ${ }^{21}$; sin embargo, el 20 de febrero de 2019 se reformaría esta Ley y se eliminaría la SUPERCOM; y, la última superintendencia en integrarse a la Función de Transparencia y Control Social es la Superintendencia de Ordenamiento Territorial, Uso y Gestión de Suelo, cuya creación se dispuso en la Ley Orgánica de Ordenamiento Territorial, Uso y Gestión de Suelo, expedida en $2016^{22}$.

Dentro del aparataje institucional ecuatoriano no se introdujeron dentro de la Función de Transparencia y Control Social a

18 Publicada en el Registro Oficial Nro. 996, de 10 de agosto de 1992.

19 Publicada en el Registro Oficial Nro. 444, de 10 de mayo de 2011.

20 Publicada en el Suplemento del Registro Oficial Nro. 555, de 13 de octubre de 2011.

21 Publicada en el Suplemento del Registro Oficial Nro. 22, de 25 de junio de 2013.

22 Publicada en el Suplemento del Registro Oficial Nro. 790, de 05 de julio de 2016. 
autoridades administrativas independientes encargadas de la educación superior, estas son el Consejo de Educación Superior y el Consejo de Aseguramiento de la Calidad de la Educación Superior, tampoco a la Procuraduría General del Estado, al Instituto Ecuatoriano de Seguridad Social y tampoco a la ya extinta Agencia de Garantía de Depósitos, estas instituciones siguen funcionando a excepción de la última, manteniendo formalmente independencia de los 5 poderes en su ámbito específico.

Pero quedan en el aire una serie de órganos que no cuentan con todos los elementos de independencia como tal, para considerarse como AAI pero que cumplen con funciones de regulación y control para determinados sectores que requieren que se les dé un mayor grado de autonomía, este es el caso de las agencias ministeriales que se las denomina así por estar adscritas al ministerio de su ramo. La multiplicación de agencias ministeriales que responden directamente al Ejecutivo empezó a desarrollarse a partir de 2008, a la fecha en el país subsisten un total de 11 agencias ministeriales que se encargan de los asuntos de sectores estratégicos y sensibles tales como los hidrocarburos, energía, minas, telecomunicaciones, salud, el agua, el régimen postal, entre otras ${ }^{23}$.

Estas agencias de regulación y control ministerial están encargadas de ser el órgano técnico de su respectivo ministerio para proveerle de insumos científicos de las decisiones que se tomen, de ahí que aquí se encuentra el grueso de profesionales específicos en el sector

23 Las agencias de regulación y control que existen en el ordenamiento ecuatoriano son: Agencia de Regulación y Control Minero (ARCOM), Agencia de Regulación y Control Hidrocarburífero (ARCH), Agencia de Regulación, Control y Vigilancia Sanitaria (ARCSA), Agencia de Regulación y Control Minero (Agencia Postal), Agencia de Regulación y Control Fito y Zoosanitario (AGROCALIDAD), Agencia de Regulación y Control de las Telecomunicaciones (ARCOTEL), Agencia de Regulación y Control de Electricidad (ARCONEL), Agencia de Aseguramiento de la Calidad de los Servicios de Salud y Medicina Prepagada (ACESS), Agencia de Regulación y Control de la Bioseguridad y Cuarentena para Galápagos, Agencia Nacional de Tránsito (ANT), Agencia de Regulación y Control del Agua (ARCA). 
y si bien no se especifica que sus informes son vinculantes, por su carácter técnico, es casi obligatorio para los ministerios.

A más de eso se les ha facultado la capacidad reglamentaria en asuntos técnicos de los sectores a los que se les vincula y cuentan con capacidad sancionatoria con resoluciones en firme en instancia administrativa, es decir sus sanciones no pueden ser recurridas ante el ministro, lo cual le da una cierta autonomía administrativa. A pesar de lo señalado, no se les ha incluido como AAI en toda regla, debido a la falta de autonomía financiera y por la conformación de sus titulares, la cual suele hacerse por libre nombramiento y remoción del Ejecutivo, con un Directorio conformado íntegramente por funcionarios ministeriales, por eso estas instituciones se quedarían a medio camino y no estarían exentas de contar con neutralidad política reforzada.

A estas instituciones no consideradas AAI, se pueden sumar los Consejos Nacionales de Igualdad que, si bien se conforman de forma paritaria por representantes de la sociedad civil y del Estado, son presididos por el delegado de la Función Ejecutiva y en el Organigrama Institucional pertenecen a esta ${ }^{24} \mathrm{y}$ no tienen autonomía administrativa y financiera, de ahí que no se profundiza en estos.

\section{Función de Transparencia y Control Social}

\subsection{Constitución 2008}

La Constitución de la República del Ecuador de 2008 es el producto de una nueva crisis del Estado, en este caso del Estado neoliberal. La indignación popular en contra de la clase política y la ingobernabilidad que se produjo en el país desde 1997 allanó el camino para que un proyecto político rupturista irrumpiera en las elecciones presidenciales, consagrando al candidato Rafael Correa como Presidente.

24 Véase los artículos 156 y 157 de la Constitución ecuatoriana. 
Dar de baja a la "neoliberal" Constitución de 1998 y, consecuentemente, el llamado a una Asamblea Nacional Constituyente fueron algunas de sus principales promesas de gobierno.

El proceso para elegir constituyentes se llevó a cabo en octubre de 2007, con un resultado muy favorable al movimiento político del Presidente Correa, con 80 de los 130 asambleístas constituyentes a su favor (Paz y Miño, 2008). Finalmente, el 25 de julio de 2008 la Asamblea aprobó el nuevo proyecto de Constitución, que fue ratificado mediante consulta popular ${ }^{25}$.

Tal como las constituciones de Bolivia y Venezuela, la Constitución ecuatoriana se considera como el producto de la corriente neoconstitucional latinoamericana, con un carácter pluralista y transformador que afirma la identidad latinoamericana. Este enfoque busca hacer una propuesta de descolonización en el ámbito epistemológico que ofrece una diferenciación de las teorías constitucionales de Estados Unidos y de Europa, diferente a postulados que asumen la doctrina de países más desarrollados como válidas, de manera irreflexiva, propagada por constitucionalistas que postulan su "sofisticación teórica" por medio de la colonialidad intelectual (Wolkmer \& Radaelli, 2017, p.44). De ahí que el actual Juez de la Corte Constitucional del Ecuador, Ramiro Ávila Santamaría, con los caracteres y problemática exclusivos de Latinoamérica y su región andina, señala que la Constitución de 2008 es un claro representate del neoconstitucionalismo andino o neoconstitucionalismo transformador, el cual ofrece respuestas más completas a las que otros neoconstitucionalismos del "norte" ofrecen, para la realidad ecuatoriana (Ávila, 2011).

25 En el referéndum de 28 de septiembre de 2008 participó más del 75\% de los electores; ante la pregunta: "¿Aprueba usted el texto de la nueva Constitución Política de la República elaborado por la Asamblea Constituyente?”, el 63,93\% de los votos fueron a favor de la Constitución, y el 28,10\% en sentido negativo; los votos en blanco y nulos fueron el 7,98\%. De acuerdo con la disposición derogatoria del nuevo texto constitucional, quedaba abrogada la Constitución de 1998. 
A breves rasgos, entre las innovaciones de la Constitución 2008 aprobada en la ciudad ecuatoriana de Montecristi, estaba la creación de una estructura institucional-constitucional más amplia que una mera carta política de derechos; se establecieron una serie de objetivos comunes para la sociedad articulados en torno a la incorporación de un sistema axiológico constitucional (sumak kawsay², derechos de la naturaleza, algunos derechos para minorías étnicas, derechos para la comunidad LGBTI.) que dan vida propia al mandato constitucional y crean una institucionalidad novedosa destinada a consolidar un mejor gobierno y una aplicación directa de las normas constitucionales (Martínez, 2017, p.99). Se implementó un nuevo sistema de control constitucional mixto, se atribuyeron derechos a la naturaleza; una extensa Constitución que define al Ecuador en su artículo 1 como un Estado "constitucional de derechos y justicia, social, democrático, soberano, independiente, unitario, intercultural, plurinacional y laico". Además, se incluyeron de forma adicional al Ejecutivo, Legislativo y Judicial, la Función Electoral y la Función de Transparencia y Control Social y la Función Electoral como ruptura al Estado tripartito clásico.

A pesar de este esperanzador afán participativo e indudablemente ante la percepción de vientos de cambio, el periodo que prosiguió a la entrada en vigencia de esta neoconstitucional andina Constitución de 2008 se vería empañado por una acumulación cada vez más vertiginosa de poder político en el Ejecutivo y tergiversación de los textos constitucionales, al respecto afirma Roberto Gargarella:

26 El Sumak Kawsay, es una cosmovisión ancestral de la vida, que procede de los pueblos originarios de los Andes americanos. Desde finales del siglo XX es también un paradigma epistémico y una propuesta política, cultural y social desarrollada en Ecuador y Bolivia. En Ecuador la expresión se ha traducido del kichwa/quechua erróneamente como "buen vivir", lo más acertado sería "vivir en plenitud". A breves rasgos, se refiere a una serie de principios vinculados con el desarrollo personal, espiritual y económico en plenitud, equilibrio y armonía con la naturaleza como alternativa al desarrollo tradicional. Si bien el concepto se incluyó en la Constitución ecuatoriana de 2008 y la boliviana de 2009, sería una aún un concepto en construcción. Véase (Acosta, 2008). 
(...) la práctica inmediata que siguió a la aprobación de la Constitución reafirmó cada una de las sospechas señaladas. De manera nada sorprendente, fue el propio presidente de la República quien puso límites a la participación popular, desalentando la organización ciudadana que la Constitución alentaba, o directamente vetando las iniciativas legislativas destinadas a poner en marcha los institutos creados en los debates de Montecristi. (Gargarella, 2011, p.297).

\subsection{La Función de Transparencia y Control Social (FTCS)}

Según Rubén Martínez Dalmau la Función de Transparencia y Control Social (FTCS) es un nuevo poder cuya existencia ya fue debatida en otros procesos constituyentes anteriores en Latinoamérica, estos son los casos de Colombia en 1991, en el mismo Ecuador en 1998 y en Venezuela en 1999 donde se incorporaría el Poder Electoral y el Poder Ciudadano (Martínez, 2017). A esto yo añadiría dos antecedentes, el Poder Moral propuesto por Simón Bolívar en 1819 para incorporarse en la Gran Colombia ${ }^{27}$ y la Constitución peruana de 1993, que como fue visto en el apartado específico, cuenta con órganos equiparados expresamente con los poderes del Estado, sus órganos constitucionalmente autónomos.

27 Ante el Congreso de Angostura, Bolívar propuso la creación de un "Poder Moral" o moderador, ejercido por un "Areópago” dividido en dos cámaras. La primera se encargaría de promover la moral en toda la República y la segunda estaba dedicada a la educación. El Areópago era, en realidad, un poder de control de la ética pública y promoción educativa y cultural. Era elegido por el Congreso, pero funcionaba con independencia. Para la Constitución de Bolivia, el Libertador propuso que el Congreso tuviera tres cámaras. La tercera sería de la de los "censores", con poderes de control, especialmente sobre el presidente de la República. (Ayala, 2018, p.211). Esta idea habría sido presentada pues los congresos se reunían en lapsos más dilatados de tiempo por las distancias de los departamentos de la Gran Colombia de ahí que, en estos recesos, las cámaras del Parlamento no podían ejercer sus funciones de control gubernamental. 
La FTCS se conforma por el Consejo de Participación Ciudadana y Control Social, la Defensoría del Pueblo, la Contraloría General del Estado y las superintendencias. Hasta la enmienda constitucional de 2018, los titulares de estas instituciones, con excepción de las superintendencias, eran seleccionados mediante concurso público de oposición y méritos. Entre sus titulares se conforma una instancia de coordinación, y elegirán de entre ellos, cada año, a la Presidenta o Presidente de la Función.

Concretamente, la Constitución 2008 establece en su artículo 204 al respecto:

La Función de Transparencia y Control Social promoverá e impulsará el control de las entidades y organismos del sector público, y de las personas naturales o jurídicas del sector privado que presten servicios o desarrollen actividades de interés público, para que los realicen con responsabilidad, transparencia y equidad; fomentará e incentivará la participación ciudadana; protegerá el ejercicio y cumplimiento de los derechos; y prevendrá y combatirá la corrupción. (CRE)

De la exégesis de este artículo se evidencia que la FTCS se crea como un contrapeso de control a los demás poderes, sin embargo, este control iría vinculado directamente con la participación ciudadana, es decir la Constitución prevé un contrapeso que se aleje de las luchas político-partidistas y se integre por ciudadanos sin afiliación política, lo cual haría que no estén infectados por ese afán de llevarse el botín político y actuaran sin influencia de intereses de grupo.

Gargarella en 2011 afirmaba que la construcción constitucional de la Función de Transparencia y Control Social sería inconveniente "por contener o directamente diluir, antes que asegurar y promover, la participación ciudadana, que queda encorsetada en una serie de burocráticos mecanismos estatales" (Gargarella, 2011, p.296). Es decir, que al momento de que estos "simples ciudadanos" se conviertan en burócratas y autoridades, indefectiblemente entrarán a formar parte del juego político tan venido a menos. En este sentido dice Juan Pablo Aguilar que para él "Una nueva función del Estado no es sociedad participando; es, ante todo y sobre 
todo, institucionalidad pública y, como tal, Estado." (Aguilar, 2009, p.97). Por esto, la FTCS no es una instancia de poder popular como se nos presenta en el discurso gubernamental, sino que lo único que hace es agrupar a los tradicionales órganos de control en una Función nueva a la que se asigna un nombre largo y rimbombante.

Con todo esto, sería inviable afirmar que las AAI que surgieron en el Ecuador se agruparon dentro de la FTCS como un intento de sellar su independencia, más bien la implementación de un nuevo poder serviría de disfraz para el Poder Ejecutivo de influir de manera más directa y disfrazada en diferentes ámbitos estatales.

\subsection{El Consejo de Participación Ciudadana y Control Social (CPCCS)}

El Consejo de Participación Ciudadana y Control Social (CPCCS) heredaría el trabajo y las obligaciones de la Comisión de Control Cívico de la Corrupción (CCCC) creada en 199728. Este Consejo es el encargado de designar a los titulares de algunas AAI: el Procurador General y Superintendentes a propuesta del Presidente de la República; el Defensor del Pueblo, el Defensor Público, el Contralor, el Procurador General del Estado, el Fiscal General, los miembros del

28 La Comisión del Control Cívico de la Corrupción (CCCC) se creó mediante Decreto Ejecutivo Nro. 107-A, de 4 de marzo de 1997, con el propósito de canalizar la participación de la sociedad civil en procesos de denuncia, investigación y prevención de la corrupción. Esta Institución estuvo conformada por cinco miembros de la sociedad civil nombrados por iniciativa del Presidente de la República y tres miembros nombrados por iniciativa del Presidente del Congreso Nacional. Posteriormente, en la Constitución 1998 dentro de los organismos de control se contemplaba a la CCCC, y se la definió como una persona jurídica de derecho público, con autonomía e independencia económica, política y administrativa que promovía la eliminación de la corrupción; receptaba denuncias sobre hechos presuntamente ilícitos cometidos en las instituciones del Estado, para investigarlos y solicitar su juzgamiento y sanción. Se dejó por sentado que su accionar no interferiría en las atribuciones de la Función Judicial. 
Consejo Nacional Electoral, del Tribunal Electoral y del Consejo de la Judicatura después del respectivo concurso público.

El artículo 207 de la Constitución publicada en 2008 señalaba originalmente que el CPCCS se integrará por siete consejeros, cuya selección se realizaría de entre los postulantes que propongan las organizaciones sociales y la ciudadanía, a través de un concurso público organizado por el Consejo Nacional Electoral. Se requería: ser ecuatoriano, en goce de derechos de participación, mayor de edad, probidad notoria reconocida por el manejo adecuado y transparente de fondos públicos, para aquellas personas que los hayan manejado; $\mathrm{y}$, desempeño eficiente en la función privada y/o pública, así como diligencia y responsabilidad en el cumplimiento de sus obligaciones.

Al revisar los requisitos mínimos exigidos para integrar este órgano me pregunto lo mismo que Ayala Mora (2018):

¿Qué certificados le hacen a uno un buen ciudadano? ¿Qué preguntas deben contestar quienes deben demostrar que son buenos ciudadanos? ¿Cómo se mide el nivel de ciudadanía? ¿Hay un mecanismo para establecer cómo una persona "sabe" ser buen ciudadano? ¿Hay un 'ciudadanómetro' en alguna parte? (p.212)

A pesar de contar con este procedimiento que parecía alejar a las otras funciones en la conformación del CPCCS no se logró este objetivo. El primer CPCCS que se posesionó en 2010 fue cuestionado por diversos sectores por falta de transparencia o irregularidades que el Consejo Nacional Electoral no logró desvirtuar nunca. Desde el primer CPCCS los "no políticos" afines al "correísmo" ganaron los concursos realizados con notas casi perfectas ${ }^{29}$. De ahí que los siete miembros elegidos del Consejo para el primer periodo que inició en 2010 hayan tenido claras vinculaciones políticas y la mayoría de

29 Como Edwin Jarrín, Vicepresidente del CPCCS, con 92 puntos sobre 100; y, también fue el caso del ex Contralor, Carlos Pólit, con una calificación de 47 puntos sobre 50, este último ahora prófugo de la justicia con acusaciones de corrupción por acciones realizadas en el desempeño de su cargo (Revista Digital GK, 2019). 
ellos fuesen cuota directa del gobierno, haciendo que no haya meritocracia posible ni democracia real.

El fin de expulsar la política no se consiguió, es por eso que Amalia Ospina acusa que las prácticas políticas de la "vieja partidocracia", para la conformación de los organismos de control entre anteriores presidentes y el ya extinto Congreso Nacional encontraron un nuevo cauce para esconderse y de alguna forma legitimarse en la funcionalidad del CPPCS. Las negociaciones políticas por poner en puestos estratégicos a personas afines al ex Presidente Rafael Correa fueron habituales. La ciudadanía que no era política de hecho se repolitizó siempre a favor del régimen con el fin de ocupar cargos (Ospina, 2012). Quienes participaron en el primer concurso para conformar el CPCCS, provinieron de los sectores movilizados y no la ciudadanía en su conjunto. A la larga, algo bastante parecido al sistema de partidos de la democracia representativa.

El segundo Consejo se instaló para el periodo 2015-2020, sin embargo, debido a escándalos de corrupción y más críticas emitidas desde muchos sectores incluyendo el nuevo Presidente de la República, contrario al régimen de Correa, Lenín Moreno (2017- 2021), se impulsó desde el Ejecutivo una consulta popular y enmienda para modificar al CPCCS.

\subsection{La enmienda constitucional de 2018 .}

En octubre de 2017, el Presidente de la República, Lenín Moreno, ya a todas luces contrario a Correa ${ }^{30}$, anunció que llevaría a cabo una

30 Luego de un cambio presidencial en el que el sucesor de Correa, Lenin Moreno, quien inicialmente y en campaña se presentó como perteneciente a su misma línea política, a pocos meses de su posesión, Moreno inició un paulatino distanciamiento del régimen anterior por cómo recibió el país luego de una década en el poder de su antecesor, situación agravada por una serie de escándalos de corrupción que expusieron a varias altas autoridades del gobierno anterior y partidos de ideologías más tradicionales que apoyaron al nuevo régimen. 
consulta popular y referéndum constitucional ${ }^{31}$, que finalmente se realizó el 4 de febrero de 2018. En lo concerniente a la FTCS, la tercera pregunta del referéndum constitucional señalaba:

¿Está usted de acuerdo con enmendar la Constitución de la República del Ecuador para reestructurar el Consejo de Participación Ciudadana y Control Social, así como dar por terminado el periodo constitucional de sus actuales miembros y que el Consejo que asuma transitoriamente sus funciones tenga la potestad de evaluar el desempeño de las autoridades cuya designación le corresponde, pudiendo, de ser el caso, anticipar la terminación de sus períodos de acuerdo al Anexo 3?. (2018).

El Anexo 3, a más de cesar a los consejeros del CPCCS e implantar un Consejo Transitorio, modificó los artículos 205 y 207 de la Constitución al establecer que las consejeras y consejeros serán elegidos por sufragio universal, directo, libre y secreto cada cuatro años coincidiendo con las elecciones a las autoridades de los gobiernos autónomos descentralizados ${ }^{32}$. Para postularse deberán

31 De conformidad con el artículo 441 de la Constitución de la República del Ecuador la enmienda de la Constitución se podrá realizar mediante referéndum solicitado por el Presidente de la República o por la ciudadanía con el respaldo de al menos el ocho por ciento de las personas inscritas en el registro electoral. En síntesis, el referéndum es una especie del género consulta popular. La consulta popular no ha sido definida expresamente en la Constitución; sin embargo, se lo reconoce en el artículo 103 se lo reconoce como mecanismo de democracia directa, junto con la iniciativa popular normativa (art. 103), la consulta popular (art. 104) y la revocatoria del mandato (arts. 105 y 106). De ahí que la consulta popular consiste en plantear un número de preguntas al pueblo, mientras que el referéndum versa sobre un cuerpo jurídico o algún asunto definido, existiendo un anexo o un archivo adjunto sobre lo que se va a preguntar al pueblo, lo que implica un posterior cambio y perfeccionamiento a la Constitución. La consulta popular son preguntas que se realizan al pueblo en temas relevantes, su característica principal es que no contienen ningún texto de reforma, solo se consulta y se aplica, en cambio el referéndum, contiene un texto adjunto, que una vez aprobado enmienda la Constitución.

32 Las elecciones de gobiernos autónomos descentralizados se realizan cada 4 años, siendo la última la que se llevó a cabo en marzo de 2019. Esto origina que las 
ser ciudadanas y ciudadanos con trayectoria en organizaciones sociales, en participación ciudadana, en la lucha contra la corrupción o de reconocido prestigio que evidencie su compromiso cívico y de defensa del interés general. Las consejeras y consejeros no podrán ser afiliados, adherentes o dirigentes de partidos o movimientos políticos, durante los últimos cinco años. Esta pregunta contó con el voto favorable (CNE, 2018).

Las reformas a la Constitución de 2018 se enfocaron en el régimen de elecciones para la conformación del CPCCS que pasaron de un sistema de selección a uno de sufragio universal y procesos derivados de éste, redefiniendo el periodo de sus miembros a 4 años; modificación de requisitos para ser consejero, aumento de las prohibiciones; terminación anticipada de los cargos de los miembros del CPCCS en funciones; conformación de un Consejo Transitorio; evaluación de las autoridades designadas por el CPCCS y posibilidad de un cese anticipado de sus funciones. El Consejo Transitorio ${ }^{33}$ sería el encargado de realizar las acciones para cumplir con el mandato popular votado por la ciudadanía (Jara, 2019).

Con la enmienda se pretendía legitimar de manera democrática al CPCCS, para paliar las críticas de falta de legitimación democrática, pero corresponde preguntarnos si en verdad el CPCCS es una AAI. El criterio técnico de las autoridades ya no sería un factor para encasillarla como un elemento de tecnocracia para obtener mejores

elecciones de las autoridades del CPCCS se organicen 2 años posteriores a las elecciones de presidenciales y de asambleístas, cuya última posesión fue en mayo de 2017.

33 Capítulo aparte merece el CPCCS Transitorio posesionado el 28 de marzo de 2018, el cual si bien contó inicialmente con una inmensa simpatía popular por la labor anticorrupción que ejerció y el intento de construir un mecanismo de participación autónomo, sin la injerencia de los poderes del Estado (Páez \& Rodríguez, 2018, p.11), desde varias voces también se lo acusó de extralimitarse en sus funciones, abuso de poder, el cese de autoridades que no designaba y la ejecución de investigaciones que eran competencia de la Contraloría General del Estado y no del CPCCS (Jacho \& Ronquillo, 2019). 
resultados, sino que el sufragio universal decidiría quién es el mejor ciudadano para ocupar este cargo.

Así como el examen que estaba ideado para el original CPCCS no mostraba quien era un mejor ciudadano, la votación popular tampoco sería el mecanismo adecuado. Es más, expone a que una institución que estaba alejada al juego político busque llevar el mensaje de los candidatos a partir del sistema de partidos, que son quienes manejan estrategias e infraestructuras institucionales para llevar mensajes al electorado. Con esta modificación, desde mi punto de vista, las puertas están abiertas para que los partidos políticos interfieran de forma más visible en la FTCS: en este escenario considerar que el CPCCS sería un órgano revestido de neutralidad política sería una aseveración por lo menos temeraria.

El 24 de marzo de 2019 se efectuaron las primeras elecciones del CPCCS, con los 7 candidatos electos, el 13 de junio de 2019 se instalaría el tercer pleno del CPCCS, esta vez democrático. Entre las principales críticas que se esgrimieron en contra del Presidente del organismo, José Tuárez, la Vicepresidenta Rosa Chalá, el Consejero Walter Gómez y la Consejera Victoria Desintonio, es que habían sido apoyados frontalmente por el partido político del ex Presidente de la República, Rafael Correa.

El 14 de agosto de 2019 la Asamblea Nacional, luego de un juicio político llevado en contra de estos cuatro Consejeros, los destituyó por irregularidades en sus hojas de vida (Vélez, 2019) y por el incumplimiento del Dictamen de la Corte Constitucional Nro. 2-19-IC/19, de 07 de mayo de 2019 que prohibía la revisión de las actuaciones realizadas por el CPCCS Transitorio ${ }^{34}$.

34 En el literal e del inciso 84 correspondiente a la decisión del Dictamen de la Corte Constitucional Nro. 2-19-IC/19, de 07 de mayo de 2019 (pág. 19), al respecto la Corte Constitucional señala: El Consejo de Participación Ciudadana y Control Social definitivo no ostenta las competencias extraordinarias que el 'Régimen de transición del Consejo de Participación Ciudadanía y Control Social' otorgó al Consejo transitorio. Por tal razón, no goza de autotutela para 


\subsection{Constitucionalización de las AAI}

La Constitucionalización de las autoridades administrativas independientes se presenta en ocasiones como fórmula para superar los déficits de legitimidad constitucional (Delcros, 1988, p.467). La constitucionalización de las autoridades independientes, sea a través de órganos sin clasificación o incluso dentro de la creación de una Función o Poder, se hace como un intento de frenar el reparto político del Ejecutivo y del Legislativo en el nombramiento de los órganos que los auditan y que se encargan de funciones muy específicas de interés del Estado.

Es así por ejemplo que Aguilar Andrade señalaba que el hecho de incluir a la Contraloría, Superintendencia y otros órganos de control dentro del texto constitucional, más obedecía a razones históricas que a razones prácticas para salvaguardar su legitimidad. Para este autor, no habrían razones de fondo para dar a estas AAI un tratamiento distinto del que se concede a otros organismos de regulación y control de actividades privadas (Aguilar, 2007, p.102). Lo cual como se ha visto, no sería del todo acertado pues las AAI son heterogéneas en las labores que cumplen y no se constriñen necesariamente a ser organismos de control, además no podrían confundirse con órganos ministeriales o ejecutivos por la distinta naturaleza que poseen, además de su difícil clasificación y refuerzo en su neutralidad política. Lo afirmado por Aguilar se haría un año antes del establecimiento de la Función de Transparencia y Control Social.

Un año después a la implementación de la FTCS, el mismo Juan Pablo Aguilar afirmaría que el sistema implementado en 2008 le da excesiva confianza al sistema cuasi corporativo del concurso de oposición y méritos. Para él, es poco probable establecer un sistema matemático que permita encontrar al funcionario ideal. Además, el

revisar las decisiones tomadas por el Consejo transitorio en ejercicio de aquellas. En consecuencia, el Consejo de Participación Ciudadana y Control Social definitivo está sujeto de manera íntegra a las reglas constantes en el artículo 208 numerales 10, 11 y 12 y artículo 209 de la Constitución. 
principal problema del Consejo de Participación Ciudadana y Control Social es que necesitaba establecer renovaciones parciales de los cuerpos colegiados y periodos distintos para el ejercicio de las funciones de ciertas autoridades, cosa que sí hace la Constitución, permitiendo con ello que la elección de un nuevo Presidente no se convierta en la ocasión ideal para reorganizar completamente las cortes y los organismos de control (Aguilar, 2009, pp.101-102).

Esto efectivamente se cumpliría en 2018, pero como hemos visto por cualquiera de los medios aún es un reto reforzar la neutralidad política del CPCCS y por ende al resto de la FTCS. Por eso considero que el mejor sistema, cualquiera que sea este, es el que quienes nombran y sean nombrados como autoridades independientes, asuman esta característica en el desempeño de sus acciones y no terminen como instrumentos de manipulación y rédito político. Si no se puede cumplir esto significaría que el mismo sistema de partidos y la temida "partidocracia", no es que hayan sido combatidas sino que se han revitalizado a través de mecanismos mejor engrasados y más difíciles de ser comprendidos y, por lo mismo, criticados.

El establecimiento de un nuevo sistema que en la teoría prometedora permitía premiar a quienes sean mejores ciudadanos, ciudadanos menos contaminados por la política, mejor preparados, con mayores méritos profesiones y al mismo tiempo castigar a quienes convirtieron a la Administración en una cloaca que llevó al país a ser de los más corruptos de la región y del mundo, y en la práctica ya con más de 10 años de su establecimiento, comprobar que la corrupción mutó en nuevas y más complejas formas de enquistarse en la Administración, es un acto de hipocresía que nació de un discurso gubernamental que tuvo como principal amplificador a la propia Constitución. A la vista ya se ven nuevos retos de la renovada Función de Transparencia y Control Social y sus órganos, pero en los escasos dos años que han pasado, a pesar de solventarse la legitimación política, se ha visto que la independencia es un adjetivo muy fácil de colocarlo en el papel, pero muy difícil de asumirlo cabalmente. 


\section{Conclusiones}

El aparecimiento de las agencias y autoridades administrativas independientes se origina como una ruptura a los poderes tradicionales en los cuales la mayoría de Estados se ha dividido, de ahí que la crítica deriva en donde encasillarlos efectivamente. La ruptura de los poderes clásicos se ha visto influida por la crisis del Estado Liberal y un afán más intervencionista de la Administración.

Las AAI son instituciones pertenecientes al sector público que cuentan con un grado de independencia en su permanencia, institucionalización, financiamiento, que las aleja de la arena política donde confluyen los poderes clásicos del Estado, cuentan con un carácter técnico de sus autoridades, en síntesis son órganos tecnocráticos que regulan determinados sectores.

Las características identificadas de las AAI son las siguientes: personas jurídicas distintas al Estado, con personalidad jurídica propia, con autonomía para su auto organización; de gestión personal a su servicio; y de auto disposición sobre sus medios patrimoniales; las normas por las cuales se rigen son especiales y privativas; son instituciones independientes, esto es que no están sujetas al poder de tutela y de dirección a las cuales el resto de instituciones se someten; los representantes de las AAI deberían contar con un periodo fijo en su cargo y solo podrían ser removidos del mismo por causales muy específicas para garantizar su independencia; con potestades sustantivas para la regulación y el control de un sector determinado; reforzadas en su neutralidad política; y, que no son identificables dentro de un poder clásico del Estado.

Los orígenes históricos de las AAI están en los Estados Unidos de América a partir de la construcción jurisprudencial realizada a través de las instituciones que se fugaban de los poderes ejecutivo y legislativo de ese país y que se fueron incrustando poco a poco desde el siglo XVIII. A través de la Deferencia jurisprudencial Chevron se ha catapultado la facultad interpretativa de las agencias por sobre las que se realizaren por jueces, de ahí la importancia que tienen y su constante controversia. 
En el Ecuador y Latinoamérica, a inicios del siglo XX y con la influencia estadounidense de la Misión Kemmerer se empezaron a ver las primeras AAI.

El aparecimiento de las primeras AAI en el Ecuador se generó a partir de 1927 en el sector financiero y bancario (Banco Central, Contraloría y Superintendencia de Bancos), en los años 60 en el sector corporativo con la Superintendencia de Compañías. A esto le seguiría en los años 90 una superintendencia encargada de las telecomunicaciones y la Comisión de Control Cívico de la Corrupción.

La Constitución 2008 contiene 2 poderes diversos a los tres clásicos, entre ellos, la Función de Transparencia y Control Social (FTCS). La FTCS está ideada de insertar la participación ciudadana en el sistema de rendición de cuentas y control social. Sus instituciones son algunas de las AAI identificadas y su eje central es el Consejo de Participación y Control Social (CPCS).

El CPCCS es una AAI que en un inicio se conformó por miembros con concurso de oposición y méritos, trató de apartárseles de la denostada "partidocracia", justamente para realizar su labor de control. Se encarga entre otras cosas de la designación del resto de autoridades de la FTCS y de titulares de otras instituciones tal como la Corte Constitucional, el Consejo Nacional Electoral y la Procuraduría General del Estado.

Desde un inicio los criterios técnicos para escoger a los consejeros del CPCCS estuvieron en tela de duda, pues no hay una fórmula objetiva para determinar a los mejores ciudadanos y menos políticos al mismo tiempo. Esto era una contradicción pues si bien el CPCCS nombraba a otras autoridades como superintendentes y Contralor, estos sí contaban con criterios más objetivos como su preparación e investigación, a pesar de esto para estos cargos técnicos, se mantuvo la fórmula de designación a partir de ternas remitidas por el Ejecutivo directamente a la Función de Transparencia y Control Social sin pasar por el Legislativo. Lo cual dejó la puerta abierta para negociación política que es lo que justamente se buscaba eliminar. Por eso la meritocracia podría ser un sistema más aplicable 
para la designación de autoridades administrativas independientes encargadas de sectores técnicos como superintendencias, Contraloría General del Estado, Defensoría del Pueblo, etc.

Por las críticas sufridas a la legitimación democrática de sus miembros, en 2018 se realizó una enmienda constitucional para que los miembros del CPCCS se elijan a través de sufragio universal. Con esto se dio protagonismo al sistema de partidos en la elección de autoridades y si bien ahora existe legitimación democrática, la neutralidad política fue ostensiblemente disminuida.

Las AAI en el Ecuador cuentan con muchos requisitos formales y es más, los intentos por dotarse de independencia han sido subidos al nivel constitucional, sin embargo esta independencia, por lo menos hasta antes de 2018, parece ser exigua.

El establecimiento de la FTCS en sus primeros 10 años no fue una solución a la independencia en el ámbito de las AAI, permitió que el Ejecutivo tenga una incidencia mayor, y a más de eso reflejó que una vez que el ciudadano común (no político) entra dentro de la Administración, se repolitiza.

La creación de la FTCS no sirvió como un ente neutralizador político de las AAI que acogió en su seno, de hecho, sirvió para comprobar que la corrupción mutó en nuevas y más complejas formas de enquistarse en la Administración.

Independientemente de la organización constitucional, la garantía de la independencia, neutralidad política y eficacia nace en que las AAI no se las asuma como instrumentos de reparto, manipulación y rédito político. Si esto no es cumplido y no se realizan acciones en esa dirección, lamentablemente todas las características estudiadas en este mismo trabajo simplemente significarían nuevas formas en las que el sistema de partidos ha conseguido acumular más poder. 


\section{Referencias Bibliográficas}

Acosta, A. (2008). El buen vivir, una oportunidad por construir. Ecuador Debate. Innovaciones y retos constitucionales (75), 33-47.

Aguilar, J. P. (2007). Compromiso político y organismos de control. Foro: revista de Derecho, 97-110.

Aguilar, J. P. (2009). La cuarta función del Estado. Análisis de una ficción. En S. Andrade, A. Grijalva, \& C. Storini, La Nueva Constitución del Ecuador. Estado, derechos e instituciones (págs. 93-104). Quito: Corporación Editora Nacional.

Aguilar, J. P. (2018). El mito del nuevo paradigma constitucional. Quito: Corporación de Estudios y Publicaciones.

Alemán, P. (2002). Banco Central del Ecuador: La Historia que aún no aprendemos. Guayaquil: Instituto Ecuatoriano de Economía Política. Recuperado el 12 de abril de 2020, de http://www.hacer.org/pdf/Romero01.pdf

Ávila, R. (2011). El Neoconstitucionalismo transformador. El Estado y el derecho en la Constitución de 2008. Quito: Editorial Abya Yala.

Ayala, E. (2018). El "Poder" que está demás: cómo la Constitución vigente consagró un retroceso democrático y un atropello al principio de representación con el "Cuarto Poder". En G. Benavides Llerena, \& C. Reyes Valenzuela, Horizonte de los derechos humanos: Ecuador 2014-2016 (págs. 209216). Quito: Abya Yala.

Ayala, A. P. (2005). La larga marcha constitucional de la República Popular China: el período Mao Tse-tung. Revista de estudios políticos(129), 39-87.

Betancor, A. (1994). Las administraciones independientes. Madrid: Tecnos.

Bilbao, J. M. (1999). Las agencias independientes: un análisis desde la perspectiva jurídico-constitucional. Anuario de La Facultad de Derecho de La Universidad Autónoma de Madrid, 163-181. Recuperado de http://scholar. 


\section{El gobierno por agencias y autoridades administrativas independientes y su vinculación con la Función de Transparencia y Control Social}

googleusercontent.com/scholar?q=cache:SN5-I_sveBAJ:scholar.google. com $/ \& h l=e s \& a s \_s d t=0,5$

Clavero, B. (2005). Constitución Europea e Historia Constitucional: El rapto de los poderes. Historia Constitucional (revista electrónica) (6). Recuperado de http://hc.rediris.es/06/index.html

Consejo Nacional Electoral. (2018). Resultados del Referéndum y Consulta Popular 2018. Recuperado de http://cne.gob.ec/es/procesos-electorales/ referendum-y-consulta-popular-2018

Datla, K., \& Revesz, R. L. (2013). Deconstructing Independent Agencies (and Executive Agencies). Cornell Law Review, 98(769), 769-844. Recuperado de http://scholarship.law.cornell.edu/clr/vol98/iss4/1

Delcros. (1988). Le CSA, une nouvelle institution constitutionelle. AJDA.

Drake, P. (1995). Kemmerer en los Andes: la misión Kemmerer 1923-1933. Quito: Banco Central del Ecuador.

García de Enterría, E., \& Fernández, T. (1997). Curso de Derecho Administrativo. Madrid: Civitas.

García, E. (1993). Autoridades Administrativas Independientes y Estado de Derecho. Revista de Administración Pública (131), 61-118. Recuperado de https://scholar.googleusercontent.com/scholar?q=cache:HTAdxRNuu2IJ:scholar.google.com/\&hl=es\&as_sdt=0,5

García, M. (1987). El Estado social y sus implicaciones. En Las transformaciones del Estado contemporáneo. Las organizaciones de intereses y la teoría constitucional. Madrid: Alianza.

García-Trevijano, J. (1968). Tratado de Derecho Administrativo. Madrid: Editorial Revista de Derecho Privado.

Gargarella, R. (2011). El constitucionalismo latinoamericano y la sala de máquinas de la Constitución (1980-2010). Gaceta Constitucional (4), 89-306. 
Gozzi, E., \& Tappatá, R. (2010). La Misión Kemmerer. Fit \& Proper, 01-10. Recuperado de http://fitproper.com/documentos/propios/Mision_ Kemmerer.pdf

Gutiérrez Magaña, H. M. (2017). La institucionalización del control social en Ecuador: posibilidades y tensiones de los mecanismos participativos. Revista Chilena de Derecho y Ciencia Política, 8(2), 139-164. Recuperado de http://dx.doi.org/10.7770/rchdcp-V8N2-art1289

Jacho, P., \& Ronquillo, O. (2019). Consejo de Participación Ciudadana y Control Social transitorio en el Ecuador: facultades y atribuciones periodo 2018 - 2019. Revista Científica Mundo de la Investigación y el Conocimiento, 3 (3), 667-688. Recuperado de http://recimundo.com/index.php/es/article/view/543

Jara, I. (2019). Estudio del modelo de gestión aplicado a la transparencia y control social como Función de Estado. Caso Ecuador 2008-2018. Informe de Investigación. Universidad Andina Simón Bolívar, Sede Ecuador, Comité de Investigaciones.

Kirti, D., \& Revesz, R. L. (4 de mayo de 2013). Deconstructing Independent Agencies (and Executive Agencies). 98. Recuperado de https://scholarship.law.cornell.edu/cgi/viewcontent.cgi? referer $=\&$ httpsredir $=1 \&$ article $=3270 \&$ context $=$ clr

Lazzarato, M. (2015). Neoliberalism, the financial crisis and the end of the liberal state. Theory, Culture \& Society, 32(7-8), 67-83. Recuperado de https://journals.sagepub.com/doi/full/10.1177/0263276415600037?casa_token=XwyP55adoHgAAAAA\%3A7wfn_AmURhJ2tUo_vYGtGuckvakbfCmD45ZYWgjTvrhwwDCmE1QYQkmmxRY1XbfdtGHr6Vvv1dFL

Martínez, R. (julio-diciembre de 2017). Constitucionalismo democrático e innovación constitucional en Ecuador: la Constitución de 2008. Revista Diálogos de Saberes, Universidad Libre de Bogotá (47), 81-102. doi:https:// doi.org/10.18041/0124-0021/dialogos.47.1589 
Mashaw, J. (2006). Recovering American Administrative Law: Federalist Foundations 1787-1801. Yale Law Jornal(115), 1256-1344. Recuperado de https://digitalcommons.law.yale.edu/ylj/vol115/iss6/2/

Mashaw, J. (2008). Administration and "The Democracy" Administrative Law from Jackson to Lincoln, 1829-1861. Yale Law Journal (117), 1568-1693. Recuperado de https://www.jstor.org/journal/yalelawj

Montesquieu, J. (1942). El espíritu de las leyes. Buenos Aires: Editorial Albatros.

Naranjo, C. (Enero-Junio de 2017). Central Bank of Ecuador, 1927: among Dictatorship, Revolution and Crisis. Journal of Evolutionary Studies in Business (Universitat de Barcelona), 2(1), 128-173. doi:doi: 10.1344/ jesb2017.1.j025

Navas, M. (2014). Proceso constiuyente, participación y un nuevo diseño democrático en la constitución ecuatoriana actual. Confluenze. Rivista di Studi Iberoamericani [S.1.], 6 (2), 94-116. doi:https://doi.org/10.6092/ issn.2036-0967/4759

Noboa, A. (27 de enero de 2015). Informe revela anomalías de selección del CPCCS. El Comercio, pág. Sección Actualidad. Recuperado de https:// www.elcomercio.com/actualidad/ecuador-informe-anomalias-seleccion-cpccs.html

Noguera, A. (2008). Participación, Función Electoral y Función de Control y Transparencia Social. En R. Ávila Santamaría, A. Grijalva Jiménez, \& R. Martínez Dalmau, Desafíos constitucionales. La Constitución ecuatoriana del 2008 en perspectiva (págs. 133-158). Quito: Ministerio de Justicia y Derechos Humanos, Tribunal Constitucional del Ecuador.

Noguera, A. (2009). El constitucionalismo de los derechos: apuntes sobre la nueva Constitución ecuatoriana de 2008. Revista Vasca de Administración Pública, IVAP(83).

Ospina, A. (2012). El gran silencio de la participación ciudadana. Revista Digital La Línea de Fuego. Recuperado de https://lalineadefue- 
go.info/2012/09/11/el-gran-silencio-de-la-participacion-ciudadana-por-amalia-ospina-palacios/

Páez, P., \& Rodríguez, A. (septiembre-diciembre de 2018). El Consejo de Participación Ciudadana y Control Social Transitorio en Ecuador: entre la legitimidad y la legalidad de sus actuaciones. Revista Internacional de Transparencia e Integridad(8).

Paz y Miño, J. J. (2008). El ciclo del proceso constituyente en Ecuador. En Constitución 2008. Entre el Quiebre y la Realidad. Quito: Ediciones Abya Yala.

Pérez, J. (enero-abril de 2011). ¿El ocaso de Chevron? Auge y fracaso de la doctrina de la deferencia judicial hacia el Ejecutivo. Revista de Administación Pública del Centro de Estudios Políticos y Constitucionales (184), 325-348. Recuperado de https://recyt.fecyt.es/index.php/RAP/article/ view/40455/23033

Pomed, L. (1993). Fundamento y Naturaleza jurídica de la Administraciones independientes. Revista de administración pública (Madrid) (132), 117-169.

Posso, R. (2016). Historia de la creación de la banca central latinoamericana. Revista de la Facultad de Ciencias Económicas y Administrativas.Universidad de Nariño, XVII (2), 166-187. Recuperado de http://www.scielo.org.co/pdf/tend/v17n2/v17n2a09.pdf

Revista Digital GK. (2019 de septiembre de 2019). Todo lo que hay que saber sobre el Consejo de Participación Ciudadana y Control Social. Obtenido de https://gk.city/2019/09/05/reforma-consejo-participacion-ciudadana/

Sánchez, H. (2015). La noción de autoridad administrativa independiente en España y en Colombia. Tesis doctoral. Universidad Carlos III de Madrid, Getafe. Recuperado de https://e-archivo.uc3m.es/bitstream/ handle/10016/22882/tesis_ha_sanchez_hernandez_2016.pdf

Sunstein, C. R. (1987). Constitutionalism after the New Deal. 101 Harvard Law Review 421. Recuperado de https://chicagounbound.uchicago.edu/ cgi/viewcontent.cgi?article $=12236 \&$ context=journal_articles 
Vázquez, V. J. (2018). Deferencia Judicial hacia las agencias federales y deferencia hacia el Legislador. La intepretación de la ley defectuosa y el principio democrático en la sentencia King V. Burwell. Revista General de Derecho Constitucional (26. Número monográfico especial).

Vélez, R. (23 de agosto de 2019). Resolución que destituyó a mayoría del CPCCS ya está en el Registro Oficial. El Comercio. Recuperado de https:// www.elcomercio.com/actualidad/resolucion-destitucion-cpccs-registro-oficial.html

Vergara, A. (julio - diciembre de 2017). Autoridades administrativas independientes (agencias): mito y realidad de un modelo conveniente para Chile. Revista de Derecho Administrativo Económico de la Universidad Católica de Chile (25), 44-58. Recuperado de redae.uc.cl/index.php/redae/ article/view/424/0

Wolkmer, A. C., \& Radaelli, S. M. (2017). Refundación de la teoría constitucional Latinoamericana: Pluralidad y descolonización. Derechos y Libertades: revista de filosofía del derecho y derechos humanos, 31-50. doi: https:// doi.org/10.14679/104 